\title{
Desempenho e Características Quantitativas de Carcaça de Novilhos Braford Desmamados aos 100 ou 180 dias de Idade e Abatidos aos 13-14 Meses ${ }^{1}$
}

\author{
Bernardo Augusto Albornoz Pötter², José Fernando Piva Lobato ${ }^{3}$
}

RESUMO - Foram determinados peso vivo ao início do período de terminação (PIT), ganho médio diário (GMD), peso de abate (PA), peso de carcaça fria (CAR), rendimento de carcaça fria (REN), espessura de gordura subcutânea (EGS) e idade de abate em dias (IA) de 32 novilhos Braford, machos castrados, previamente desmamados aos 100 (Desmame precoce - DP) ou 180 (Desmame convencional - DC) dias de idade e abatidos aos 13-14 meses de idade. Entre o DC (06/03/01) até o início do período de terminação (09/08/01), quando passaram para uma pastagem melhorada de azevém (Lolium multiflorum L.), os bezerros permaneceram em uma área de resteva de lavoura de arroz. A partir de 04/09/01, os bezerros receberam uma suplementação energética, à base de sorgo moído, até o abate, em novembro de 2001. Os animais foram abatidos conforme avaliação visual da gordura de acabamento, independentemente do peso vivo. Os novilhos do DP tiveram PIT significativamente inferior aos novilhos do DC (182,8 kg vs. 240,5 kg). Entretanto, o GMD foi significativamente superior para os novilhos DP, sendo as médias ajustadas 1,399 e 1,269 kg/dia para DP e DC, respectivamente. O PA e o CAR foram significativamente inferiores para os novilhos do DP em relação aos novilhos do DC (328,8 e 359,4 kg de peso vivo e 174,0 e 186,7 kg de carcaça fria para DP e DC, respectivamente). Os novilhos do DP tiveram REN significativamente superiores $(52,9 \%)$ aos novilhos do DC (51,9\%). Não houve efeito da idade de desmame sobre a EGS, sendo 4,91 e 4,95 mm para o DP e DC, respectivamente. A IA foi influenciada pela idade ao desmame. Os novilhos do DP foram abatidos, em média, com 430,1 dias, enquanto os novilhos do DC foram abatidos, em média, com 416,9 dias de idade.

Palavras-chave: acabamento de carcaça, idade de abate, idade de desmame, peso de abate, suplementação

\section{Performance and Carcass Traits of Braford Steers Weaned at 100 or 180 Days and Slaughtered at 13-14 Months Old}

\begin{abstract}
Live weight at the beginning of the finishing period (IFW), average daily gain (ADG), slaughter weight (SW), cold carcass weight (CCW), carcass dressing percentage (DP), subcutaneous fat thickness (SFT) and slaughter age in days (SA) of 32 castrated males Braford, previously weaned at 100 (EW) or 180 days (CW) and slaughtered at 13-14 months old, were evaluated. From CW (03/06/01) until the beginning of finishing period (08/09/01), when passed to an improved pasture of ryegrass (Lolium multiflorum L.), the calves were maintened on a rice (Oryza sativa) post-harvested paddock. From 09/04/01, the calves had a supplementary feeding, basically Sorghum vulgare, until the slaughters in november. The steers were slaughtered according the visual fatness, independently of the liveweight. The EW steers had IFW significantly lower than the CW steers $(182,8 \mathrm{~kg}$ vs. $240.5 \mathrm{~kg})$. However, the ADG was significant greater for EW steers, with adjusted means as 1.399 and $1.269 \mathrm{~kg} / \mathrm{day}$ for EW and CW, respectively. SW and CCW were lighter for EW steers (328.8 and 359.4 of live weight and 174.0 and $186.7 \mathrm{~kg}$ of cold carcass for EW and CW, respectively. The EW steers had greater DP (52.9\%) than CW steers (51.9\%). No differences were observed between treatments for SFT, being 4.91 and $4.95 \mathrm{~mm}$ for EW and CW, respectively. SA was affected by age at weaning, with EW steers slaughtered at 430.1 days and CW steers slaughtered at 416.9 days of age.
\end{abstract}

Key Words: finishing carcass, slaughter weight, supplementary feeding, slaughter age, weaning age

\section{Introdução}

A redução da idade de abate é um dos principais fatores responsáveis pelo aumento dos índices de produtividade no Rio Grande do Sul. O abate dos animais antes dos 24 meses permite aumentar a taxa de desfrute do rebanho pelo incremento no número de matrizes ao se eliminar uma categoria de recria (Pötter et al., 1998; 2000; Beretta et al., 2002b). Os animais terminados com 12-14 meses são também mais eficientes na terminação que animais terminados com 24 meses (Beretta et al., 2002a), o que reduz o custo por unidade de produto (Restle et al., 1999). Resultados de pesquisa têm demonstrado que o

\footnotetext{
${ }^{1}$ Parte da Dissertação de Mestrado do primeiro autor.

2 Médico Veterinário, Mestre em Zootecnia. E.mail: bpotter@bol.com.br

${ }^{3}$ Engenheiro Agrônomo, Ph.D., Professor Adjunto IV, Dep. Zootecnia, Fac. de Agronomia - UFRGS. Bolsista 1A-CNPq. Caixa Postal: 776, CEP: 90.001-970, Porto Alegre, RS. E.mail: lobato@orion.ufrgs.br
} 
rendimento de carcaça e de cortes comerciais diminui com o aumento na idade do animal (Costa et al., 2002a, b, c). Ou seja, as características de maior importância para o frigorífico são também beneficiadas pelo abate de novilhos a menores idades.

Além desses fatores, o mercado tem à disposição um produto de maior qualidade, já que as características organolépticas da carne (maciez, sabor, suculência) estão diretamente associadas à idade de abate do animal. Com a utilização de raças de tamanho médio, que se caracterizam pela precocidade na deposição de gordura de acabamento, é possível o abate de animais com 13-14 meses de idade, em regime de suplementação em pastagens.

Entretanto, o aumento dos índices de produtividade passa fundamentalmente também pelo aumento na eficiência reprodutiva dos rebanhos de cria (Beretta et al., 2002b). Assim, práticas de manejo têm sido analisadas, visando o aumento do desempenho reprodutivo das vacas. Práticas como o desmame dos bezerros em idades precoces (60-110 dias) têm sido utilizadas com eficácia (Santana \& Lobato, 1983; Lobato \& Barcellos, 1992; Simeone \& Lobato, 1996; Lobato et al., 2000; Vaz \& Restle, 2000; Pio de Almeida et al., 2002).

Contudo, o desenvolvimento dos bezerros desmamados precocemente é dependente do nível nutricional no período pós-desmame. Alguns trabalhos avaliaram o desempenho de novilhos desmamados à idades precoces e abatidos aos 24 meses de idade, não encontrando diferenças no ganho de peso, peso de abate e rendimento de carcaça de animais desmamados em diferentes idades (Albospino \& Lobato, 1994; Marques et al., 2001). Restle et al. (1999) avaliaram o desempenho de novilhos Braford desmamados aos 72 ou 210 dias e abatidos aos 14 meses de idade, não encontrando diferenças no desempenho em confinamento e nas características de carcaça dos animais desmamados em ambas idades. Myers et al. (1999) avaliaram o desempenho em confinamento de animais desmamados aos 90, 152 ou 215 dias e abatidos aos 14 meses de idade, verificando-se desempenho superior nos animais desmamados mais jovens.

Entretanto, são escassas as informações sobre sistemas de recria e terminação de animais desmamados antes da idade tradicional (6-7 meses) e abatidos aos 14 meses de idade em regime de terminação em pastagens. Por isto, o presente trabalho, com o intuito de criar alternativas para o produtor, teve por objetivo determinar o peso vivo ao início do período de terminação, o ganho de peso, o peso de abate, o peso de carcaça fria, o rendimento de carcaça fria, a espessura de gordura subcutânea e a idade de abate em dias, de machos Braford, castrados, filhos de vacas primíparas, terminados em regime de suplementação em pastagem e abatidos aos 13-14 meses de idade.

\section{Material e Métodos}

O experimento foi realizado na Agropecuária Caty, localizada no município de Quaraí, na Fronteira Oeste do Rio Grande do Sul, de agosto a novembro de 2001. Foram utilizados 32 bezerros Braford, machos castrados, previamente desmamados aos 100 dias de idade (desmame precoce $=$ DP), e aos 180 dias de idade (desmame convencional $=$ DC). Os bezerros do DP permaneceram em pastagem de cornichão (Lotus corniculatus cv. São Gabriel) e foram suplementados a $1 \%$ do peso vivo com concentrado comercial $(18 \%$ de proteína bruta e $74 \%$ de nutrientes digestíveis totais) até a data do DC (06.03.2001). A partir desta, todos os bezerros formaram um único lote, sendo manejados em uma resteva de lavoura de arroz (Oryza sativa) até 09/08/2001, quando passaram a um potreiro com pastagem de azevém (Lolium multiflorum L.).

Em 04.09.2001, os animais passaram a receber uma suplementação à base de sorgo moído (Sorghum vulgare), no nível de $1 \%$ do seu peso vivo, uma vez ao dia (Tabela 1).

Os animais foram pesados após jejum prévio de 12 horas, no início do experimento, a cada 28 dias e por ocasião do abate, para determinação do ganho

Tabela 1 - Composição do concentrado na fase de terminação

Table 1 - Supplementary feeding composition in the finishing period

\begin{tabular}{|c|c|}
\hline $\begin{array}{l}\text { Ingredientes } \\
\text { Ingredients }\end{array}$ & $\begin{array}{c}\text { Quantidade (\%) } \\
\text { Amount (\%) }\end{array}$ \\
\hline $\begin{array}{l}\text { Sorgo } \\
\text { Sorghum }\end{array}$ & 97,21 \\
\hline $\begin{array}{l}\text { Fosfato bicálcico } \\
\text { Dicalcium phosphate }\end{array}$ & 1,00 \\
\hline $\begin{array}{l}\text { Calcário } \\
\text { Limestone }\end{array}$ & 1,74 \\
\hline $\begin{array}{l}\text { Limestone } \\
\text { Monensina } \\
\text { Monensin }\end{array}$ & 0,05 \\
\hline Total & 100,00 \\
\hline
\end{tabular}


médio diário (GMD). O critério para o abate foi a avaliação visual de gordura subcutânea, independentemente do peso vivo dos animais. Metade dos animais foi abatida em 04.11.2001 e a outra metade, em 28.11.2001.

A avaliação das carcaças foi realizada após 24 horas de resfriamento a $1^{\circ} \mathrm{C}$ (Müller, 1987), a qual constou de pesagem das carcaças (CAR) e, a partir de um corte transversal na $12^{\mathrm{a}}$ vértebra torácica, mediu-se a espessura de gordura subcutânea (EGS).

O experimento foi analisado segundo um delineamento completamente casualizado. As variáveis de resposta contínua, com distribuição considerada normal, foram analisadas mediante análise de variância. As diferenças entre as médias ajustadas foram testadas pelo teste Tukey.

O peso vivo dos novilhos ao início do período de terminação (PIT), ao abate (PA), o GMD durante o período de suplementação, o peso de carcaça fria (CAR), o rendimento de carcaça fria (REN) e a idade dos novilhos ao abate, em dias (IA), foram analisados segundo o seguinte modelo:

$$
\mathrm{Y}_{\mathrm{jk}}=\mathrm{u}+\mathrm{ED}_{\mathrm{j}}+\mathrm{e}_{\mathrm{jk}}
$$

em que: $Y_{j k}=$ PIT, PA, GMD, CAR, REN e IA realizada no k-ésimo novilho, pertencente à j-ésima época de desmame; $\mathrm{u}=$ média geral; $\mathrm{ED}_{\mathrm{j}}=$ Efeito fixo da j-ésima época de desmame; $e_{j k}=$ Efeito residual aleatório associado à observação $\mathrm{y}_{\mathrm{jk}}$.

\section{Resultados e Discussão}

A análise de variância demonstrou efeito altamente significativo da idade de desmame $(\mathrm{P}<0,01)$ sobre o PIT, o GMD, o PA e a IA (Tabela 2).

Os novilhos do DP tiveram GMD no período de terminação significativamente superior $(\mathrm{P}<0,01)$ àqueles do DC. O fato pode ser explicado em parte pelo ganho compensatório apresentado pelos mesmos quando tiveram acesso a um suplemento de alta densidade energética e uma forragem de alta concentração protéica, como são o sorgo e o azevém, respectivamente.

Alguns trabalhos demonstraram que a qualidade da forragem após o período de restrição é de grande importância para que os animais possam expressar ganho compensatório (Meyer et al., 1965; O’Donovan et al., 1972). Segundo Drouillard et al. (1991), a variabilidade do ganho compensatório depende de questões como severidade, natureza e duração da restrição e, principalmente, pela interação entre os mesmos.
Neste trabalho, os bezerros de ambas as idades de desmame sofreram restrição alimentar antes de entrarem em regime de terminação. Por motivos climáticos, a utilização das áreas de pastagens melhoradas no ano do trabalho só foi possível em agosto, ficando os bezerros, até então, em uma área de resteva de lavoura de arroz, com baixa disponibilidade forrageira. Porém, a duração da restrição alimentar foi maior para os bezerros do DP que para os do DC, já que os mesmos encontravam-se em restrição quando foi realizado o DC, o que pode explicar em parte o melhor desempenho dos primeiros quando tiveram acesso a um alimento de alta qualidade.

Myers et al. (1999) compararam o desempenho em confinamento de bezerros de três idades de desmame: 90, 152 e 215 dias de idade. Os animais desmamados aos 90 e 152 dias apresentaram GMD significativamente maiores que aqueles desmamados aos 215 dias $(0,15 \mathrm{~kg} / \mathrm{d}$ e $0,07 \mathrm{~kg} / \mathrm{d}$ superior, respectivamente). Carstens et al. (1991) avaliaram novilhos cruza Hereford x Angus em regime de confinamento os quais foram submetidos a dois planos prévios de nutrição: em ganho restrito (GR) e em ganho contínuo (GC) durante 189 dias. Após o período de 189 dias os animais entraram em regime de confinamento, recebendo a mesma dieta, quando os animais do tratamento GR tiveram um GMD 37\% superior àqueles do tratamento GC. Os autores determinaram uma redu-

Tabela 2 - Peso ao início do período de terminação (PIT), ganho médio diário no período (GMD), peso de abate (PA) e idade de abate (IA) conforme a idade de desmame

Table 2 - Live weight at the beginning of the finishing period (IFW), average daily gain during the period (ADG), slaughter weight (SW) and slaughter age (SA) by weaning age

\begin{tabular}{|c|c|c|c|}
\hline \multirow{3}{*}{$\begin{array}{l}\text { Parâmetros } \\
\text { Parameters }\end{array}$} & \multicolumn{2}{|c|}{$\begin{array}{c}\text { Idade de desmame } \\
\text { Weaning age }\end{array}$} & \multirow{3}{*}{$\begin{array}{l}\text { Média } \\
\text { Mean }\end{array}$} \\
\hline & 100 Dias & 180 Dias & \\
\hline & 100 Days & 180 Days & \\
\hline $\begin{array}{l}\text { PIT (kg PV) } \\
I F W(k g L W)\end{array}$ & $182,8^{b}$ & $240,5^{a}$ & 211,6 \\
\hline $\begin{array}{l}\operatorname{GMD}(\mathrm{kg} / \mathrm{dia}) \\
A D G(\mathrm{~kg} / \text { day })\end{array}$ & $1,399^{\mathrm{a}}$ & $1,26^{\mathrm{b}}$ & 1,334 \\
\hline $\begin{array}{l}\mathrm{PA}(\mathrm{kg} \mathrm{PV}) \\
S W(k g L W)\end{array}$ & $328,8^{b}$ & $359,4^{\mathrm{a}}$ & 344,1 \\
\hline $\begin{array}{l}\text { IA (dias) } \\
S A \text { (days) }\end{array}$ & $430,1^{\mathrm{a}}$ & $416,9^{\mathrm{a}}$ & 423,5 \\
\hline
\end{tabular}

a,b: Médias seguidas de letras diferentes, na mesma linha, diferem $(P<0,01)$ significativamente pelo teste Tukey. $a, b$ : Means followed by different letters, in the same row, differ $(P<.01)$ significantly by Tukey test. 
ção de $18 \%$ na exigência de energia líquida para ganho durante o período de ganho compensatório em favor dos animais que sofreram restrição alimentar. De acordo com Poppi \& McLennan (1995), a razão pela qual os animais sob restrição alimentar apresentam eficiência alimentar superior, quando realimentados, se deve ao fato de o consumo de energia metabolizável ser muito superior às exigências de mantença desses animais, resultando em maior deposição protéica, maior eficiência alimentar e maior ganho de peso. Rompala et al. (1985) citam que o ganho compensatório estaria associado à maior deposição de músculo no começo da realimentação, normalizando-se com o decorrer do tempo.

Embora os bezerros do DP tenham apresentado maior GMD durante o período de terminação, os mesmos apresentaram menor PA que os bezerros do DC. Restle et al. (1999), ao avaliarem em confinamento o desempenho de machos Braford, abatidos ao 14 meses, desmamados aos 72 e 210 dias de idade, não encontraram diferenças entre idades de desmame para peso de abate. Myers et al. (1999) também não encontraram diferenças de peso vivo entre aqueles animais oriundos de desmame a idade precoce ou de desmame a idade convencional.

No presente trabalho, o PIT foi significativamente inferior para os bezerros do DP e, conseqüentemente, o PA também foi inferior. Nas referências acima citadas, os pesos iniciais dos animais eram semelhantes, o que permitiu que os animais desmamados precocemente tivessem um maior ou igual peso de abate que os desmamados à idade convencional. Neste trabalho, mesmo sendo o desempenho dos bezerros do DP superior aos do DC, os pesos vivos iniciais eram muito inferiores $(\mathrm{P}<0,01)$, conseqüência do período prévio à fase de terminação. Esse período, compreendido entre o desmame e o início da fase de terminação, foi mais longo para os bezerros do DP, 220 dias contra 156 dias para os bezerros do DC. Durante esse período de tempo, os bezerros do DP não puderam expressar ganho compensatório, só podendo expressar tal ganho mais tarde. Portanto, o período de tempo de terminação relativamente curto, não permitiu, possivelmente, que o ganho compensatório levasse esses animais a um peso de abate semelhante aos do DC.

O DP também determinou diferença significativa $(\mathrm{P}<0,01)$ na IA dos bezerros. Para cada oito dias a mais na idade ao desmame, houve diminuição $(\mathrm{P}<0,01)$ de um dia na IA $(b=-0,13)$. Este efeito da idade de desmame sobre a IA pode ser explicado pelo mesmo motivo acima descrito. Após o desmame, quando os bezerros do DP deveriam estar exibindo ganho compensatório e poderiam diminuir a diferença de peso vivo em relação aos bezerros do $\mathrm{DC}$, isso não ocorreu. Assim, o peso vivo foi influenciado e, conseqüentemente, a IA também foi retardada. Ao contrário, Myers et al. (1999) encontraram correlação positiva entre idade ao desmame e idade de abate. Ou seja, à medida que a idade de desmame aumentou, a idade de abate também aumentou, devido aos pesos vivos semelhantes ao início do período entre os dois grupos e ao menor GMD durante o período de terminação dos animais desmamados a idades mais avançadas.

$\mathrm{O}$ número de dias em terminação também foi influenciado pela idade de desmame $(\mathrm{P}<0,01)$. Para cada seis dias a mais na idade ao desmame houve uma diminuição de um dia no período de terminação $(b=-0,16)$. Esse resultado está de acordo com o observado por Myers et al. (1999), os quais também observaram decréscimo no tempo de terminação com o aumento da idade de desmame. Story et al. (2000) compararam o desempenho em confinamento de bezerros de três idades de desmame, 150 dias (DP), 210 dias (DC) e 270 dias (DT) de idade. O número de dias em terminação foi influenciado pela idade de desmame, sendo 247 para DP, 204 para DC e 164 para DT. Entretanto, a receita líquida por bezerro ao abate para a fase de confinamento foi maior para os bezerros do DP e DC em relação aos bezerros DT, devido ao fato de que, quando os dados de carcaça de DP e DC foram ajustados à mesma espessura de gordura de DT, a carcaça dos primeiros foi similar à dos últimos.

Não houve influência $(\mathrm{P}>0,05)$ da idade de desmame sobre a EGS. Outros autores também não encontraram diferença de EGS entre animais de diferentes idades de desmame (Myers et al., 1999; Restle et al., 1999), indicando que os animais desmamados precocemente têm condições de chegar ao abate aos 14 meses com adequada gordura de acabamento.

A análise de variância demonstrou efeito significativo de idade de desmame sobre CAR $(\mathrm{P}<0,01)$ e REN $(\mathrm{P}<0,05)$. As médias ajustadas estão na Tabela 3 .

Costa et al. (2002a), usando equações de regressão, citam que aos $327 \mathrm{~kg}$ de peso vivo a espessura de $3 \mathrm{~mm}$ de gordura de cobertura mínima exigida pelos frigoríficos seria alcançada, produzindo carcaças de $173 \mathrm{~kg}$. Esses valores são próximos aos observados 
Tabela 3 - Peso de carcaça fria (CAR), rendimento de carcaça fria (REN) e espessura de gordura subcutânea (EGS), conforme a idade de desmame

Table 3 - Cold carcass weight (CCW), carcass dressing percentage (DP) and subcutaneous fat thickness (SFT), as the weaning age

\begin{tabular}{lccc}
\hline & \multicolumn{2}{c}{$\begin{array}{c}\text { Idade de desmame } \\
\text { Weaningage }\end{array}$} & \\
\cline { 2 - 3 } $\begin{array}{l}\text { Parâmetros } \\
\text { Parameters }\end{array}$ & $\begin{array}{c}\text { 100 Dias } \\
100 \text { Days }\end{array}$ & $\begin{array}{c}\text { 180 Dias } \\
180 \text { Days }\end{array}$ & $\begin{array}{c}\text { Média } \\
\text { Mean }\end{array}$ \\
\hline CAR $(\mathrm{kg})$ & $174,0^{\mathrm{b}}$ & $186,7^{\mathrm{a}}$ & 180,3 \\
CCW $(\mathrm{kg})$ & & & \\
REN $(\%)$ & $52,9^{\mathrm{A}}$ & $51,9^{\mathrm{B}}$ & 52,4 \\
$\begin{array}{l}\text { DP }(\%) \\
\text { EGS }(\mathrm{mm})\end{array}$ & $4,95^{\mathrm{a}}$ & $4,91^{\mathrm{a}}$ & 4,93 \\
SFT $(\mathrm{mm})$ & & &
\end{tabular}

a,b: Na linha, diferem $(P<0,01)$ significativamente pelo teste Tukey $A, B$ : Na linha, diferem $(P<0,05)$ significativamente pelo teste Tukey.

$a, b:$ In the row, differ $(P<.01)$ significantly by Tukey test.

$A, B$ : In the row, differ $(P<.05)$ significantly by Tukey test.

no presente trabalho nos novilhos submetidos à DP, nos quais o PA foi de $328,8 \mathrm{~kg}$ de peso vivo, o de CAR foi de $174,0 \mathrm{~kg}$, com EGS de 4,95 mm. Esses resultados deixam clara a viabilidade dos animais desmamados à idades precoces chegarem ao abate aos 14 meses de idade, em regime de suplementação em pastagem, com peso de carcaça e espessura de gordura de cobertura suficientes para satisfazer o mercado interno.

O CAR foi significativamente $(\mathrm{P}<0,01)$ inferior para os novilhos do DP. Animais do DP apresentaram menores pesos vivos ao abate e, conseqüentemente, carcaças também mais leves. Entretanto, o REN foi significativamente $(\mathrm{P}<0,01)$ superior para os novilhos do DP $(52,9 \%)$ em relação aos do DC $(51,9 \%)$. Esses valores são semelhantes ao valores encontrados por Restle et al. (1999), os quais não encontraram diferença entre REN de animais inteiros abatidos aos 14 meses e desmamados aos 72 ou 210 dias de idade, 52,8 e 52,4\%, respectivamente. Esses autores, embora não tenham encontrado diferença de CAR entre tratamentos $(\mathrm{P}>0,05)$, observaram tendência dos animais desmamados aos 72 dias apresentarem CAR superior. Todavia, esses animais tinham pesos vivos superiores aos desmamados aos 210 dias (426 e $406 \mathrm{~kg}$, respectivamente).

Os maiores REN para os novilhos desmamados precocemente observados no presente trabalho estão de acordo com o exposto por Carstens et al. (1991). Esses autores avaliaram animais em ganho compen- satório ou não durante a fase de terminação em confinamento. Os animais em ganho compensatório tiveram maior rendimento de carcaça $(\mathrm{P}<0,01)$ que os animais controle. Esses animais sintetizam mais proteína, água e cinzas e $25 \%$ menos gordura na carcaça. Outro fator que explica esse maior rendimento foi o trato gastrintestinal (TGI) e as vísceras. O peso do TGI dos animais em ganho compensatório foi $24 \%$ menor que o dos animais controle e as vísceras também foram menores, com exceção do fígado, o qual foi $23 \%$ mais pesado que o fígado dos animais controle, indicando o alto desempenho mantido pelos animais durante o ganho compensatório. Segundo os autores, o período de restrição alimentar, o qual foi de seis meses, alterou significativamente a partição dos nutrientes disponíveis para crescimento, resultando em maior síntese de proteína e menor síntese de gordura na carcaça após a realimentação.

Os novilhos do DP, neste trabalho, apresentaram ganho compensatório somente na fase de terminação, ocorrendo o mesmo para os novilhos do DC. Entretanto, a restrição alimentar dos primeiros foi mais longa, pois na data do DC $(06 / 03 / 01)$ os novilhos do DP já vinham com ganhos de peso inferiores, o que pode ter determinado maior ganho compensatório, de acordo com Rompala et al. (1985).

Feijó et al. (2001), em Campo Grande, MS, avaliaram as carcaças de animais suplementados na primeira seca (S1S), na segunda seca (S2S), na primeira e na segunda seca (S12S), suplementação na primeira seca e confinamento na segunda (S1C2) e sem suplementação (SS). Embora os autores não tenham observado diferença significativa, houve tendência dos animais do tratamento S2S terem maior rendimento de carcaça, fruto do ganho compensatório no segundo ano. Entretanto, o bom nível alimentar que os animais receberam em todos os tratamentos, não permitiu serem observadas diferenças no rendimento de carcaça.

Albospino \& Lobato (1994) não encontraram diferença para PA, CAR e rendimento de carcaça quente de novilhos desmamados aos 100 e 150 dias e abatidos aos 24-26 meses de idade. Os rendimentos de carcaça quente foram de $56,1 \%$ para ambos os tratamentos. Na classificação de carcaça, o desmame aos 100 dias teve $77 \%$ dos novilhos classificados como cota Hilton, contra $66 \%$ dos desmamados aos 150 dias. Marques et al. (2001) também não observaram diferenças no peso líquido de carcaça quente e no rendimento de carcaça quente de novilhos abati-

\section{R. Bras. Zootec., v.32, n.5, p.1220-1226, 2003}


dos aos dois anos e desmamados aos 91 (DP) ou 170 (DC) dias de idade. Os valores de peso de carcaça quente e rendimento de carcaça quente obtidos foram de $208 \mathrm{~kg}$ e 50,2\%, $216 \mathrm{~kg}$ e 50,0\% para DP e DC, respectivamente. Esses resultados deixam claro a importância de um nível nutricional alto e contínuo para que os animais desmamados precocemente não tenham seu desenvolvimento comprometido. No presente trabalho, os novilhos submetidos ao DP poderiam ter tido PA e de CAR iguais ou semelhantes aos novilhos do DC caso tivessem tido uma alimentação adequada e contínua antes do período de terminação, para poderem expressar o potencial de ganho compensatório e diminuir a diferença de peso vivo em relação aos novilhos do DC.

\section{Conclusões}

O menor peso ao início da terminação dos novilhos desmamados aos 100 dias de idade fez com que os mesmos apresentassem menor peso ao abate e menor peso de carcaça em relação aos novilhos desmamados à idade convencional (180 dias).

Os novilhos desmamados aos 100 dias de idade apresentaram maior ganho médio diário no período de terminação, decorrente de maior ganho compensatório na fase de terminação em relação aos novilhos desmamados à idade convencional (180 dias).

O maior ganho médio diário dos novilhos desmamados aos 100 dias de idade proporciona maiores rendimentos de carcaça quando comparados aos novilhos desmamados à idade convencional (180 dias).

A idade de desmame não influencia a espessura de gordura subcutânea dos animais desmamados aos 100 ou 180 dias.

Os animais desmamados a idades precoces podem ser abatidos aos 14 meses de idade, em regime de suplementação em pastagem, e satisfazer os requisitos mínimos de peso de carcaça e espessura de gordura de cobertura exigidos pelo mercado.

\section{Literatura Citada}

ALBOSPINO, B.H.J.C.; LOBATO, J.F.P. Efeitos do desmame precoce de terneiros no desempenho até os 24-26 meses de idade. Revista Brasileira de Zootecnia, v.23, n.4, p.565575, 1994.

BERETTA, V.; LOBATO, J.F.P.; MIELITZ NETO, C.G.A. Produtividade e eficiência biológica de sistemas de recria e engorda de gado de corte no Rio Grande do Sul. Revista Brasileira de Zootecnia, v.31, n.2, p.696-706, 2002a.

BERETTA, V.; LOBATO, J.F.P.; MIELITZ NETO, C.G.A.
Produtividade e eficiência biológica de sistemas de produção de gado de corte de ciclo completo no Rio Grande do Sul. Revista Brasileira de Zootecnia, v.31, n.2, p.991-1001, 2002b (suplemento).

CARSTENS, G.E.; JOHNSON, D.E.; ELLENBERGER, M.A. et al. Physical and chemical components of the empty body during compensatory growth in beef steers. Journal of Animal Science, v.69, n.8, p.3251-3264, 1991.

COSTA, E.C.; RESTLE, J.; VAZ, F.N. et al. Características de carcaça de novilhos Red Angus superprecoces abatidos com diferentes pesos. Revista Brasileira de Zootecnia, v.31, n.1, p.119-128, 2002a.

COSTA, E.C.; RESTLE, J.; PASCOAL, L.L. et al. Desempenho de novilhos Red Angus superprecoces, confinados e abatidos com diferentes pesos. Revista Brasileira de Zootecnia, v.31, n.1, p.129-138, 2002b.

COSTA, E.C.; RESTLE, J.; BRONDANI, I. L. et al. Composição física da carcaça, qualidade da carne e conteúdo de colesterol no músculo Longissimus dorsi de novilhos Red Angus superprecoces, terminados em confinamento e abatidos com deferentes pesos. Revista Brasileira de Zootecnia, v.31, n.1(Suplemento), p.417-428, 2002c.

DROUILLARD, J.S.; FERRELL, C.L.; KLOPFENSTEIN, T.J. et al. Compensatory growth following metabolizable protein or energy restrictions in beef steers. Journal of Animal Science, v.69, n.2, p.811-818, 1991.

FEIJÓ, G.L.D.; EUCLIDES FILHO, K.; EUCLIDES, V.P.B. et al. Avaliação das carcaças de novilhos F1 Angus-Nelore em pastagem de Brachiaria decumbens submetidos a diferentes regimes alimentares. Revista Brasileira de Zootecnia, v.30, n.3 (Suplemento 1), p.1015-1020, 2001.

LOBATO, J.F.P.; BARCELLOS, J.O.J. Efeitos da utilização de pastagem melhorada no pós-parto e do desmame aos $100 \mathrm{ou}$ 180 dias de idade no desempenho reprodutivo de vacas de corte. Revista Brasileira de Zootecnia, v.21, n.3, p.385395, 1992.

LOBATO, J.F.P.; MÜLLER, A.; PEREIRA NETO, O.A. et al. Efeitos da idade à desmama dos bezerros sobre o desempenho reprodutivo de vacas de corte primíparas. Revista Brasileira de Zootecnia, v.29, n.6 (suplemento 1), p.20132018, 2000.

MARQUES, L.P.A.; LOBATO, J.F.P.; SCHENKEL, F.S. Efeito da idade de desmame e suplementação no desenvolvimento de novilhos de corte. In: REUNIÃO ANUAL DA SOCIEDADE BRASILEIRA DE ZOOTECNIA., 38., 2001, Piracicaba. Anais... Piracicaba: Sociedade Brasileira de Zootecnia, 2001. p.415.

MEYER, J.H.; HULL, J.L.; WEITKAMP, W.H. et al. Compensatory growth responses of fattening steers following various low energy intake regimes on hay or irrigated pasture. Journal of Animal Science, v.24, n.1, p.29-37, 1965.

MÜLLER, L. Normas para avaliação de carcaças e concurso de carcaças de novilhos. 2.ed. Santa Maria: Universidade Federald de Santa Maria, 1987. 31p. (Publicação n.1-DZ).

MYERS, S.E.; FAULKNER, D.B.; IRELAND, F.A. et al. Comparison of three weaning ages on cow-calf performance and steer carcass traits. Journal of Animal Science, v.77, n.2, p.323-329, 1999.

O'DONOVAN, P.B.; CONWAY, A.; O'SHEA, J. A study of the herbage intake and efficiency of feed utilization of grazing cattle previously fed two winter planes of nutrition. Journal of Agriculture Science, v.78, n.1, p.87-95, 1972.

R. Bras. Zootec., v.32, n.5, p.1220-1226, 2003 
PIO DE AMEIDA, L.S.; LOBATO, J.F.P.; SCHENKEL, F.S. Data de desmame e desempenho reprodutivo de vacas de corte. Revista Brasileira de Zootecnia, v.31, n.3, p.12341240, 2002.

POPPI, D.P.; McLENNAN, S.R. Protein and energy utilization by ruminants at pasture. Journal of Animal Science, v.73, n.1, p.278-290, 1995.

PÖTTER, L.; LOBATO, J.F.P.; MIELITZ NETO, C.G.A. Produtividade de um modelo de produção para novilhas de corte primíparas aos dois, três e quatro anos de idade. Revista Brasileira de Zootecnia, v.27, n.3, p.613-619, 1998.

PÖTTER, L.; LOBATO, J.F.P.; MIELITZ NETO, C.G.A. Análises econômicas de modelos de produção com novilhas de corte primíparas aos dois, três e quatro anos de idade. Revista Brasileira de Zootecnia, v.29, n.3, p.861-870, 2000.

RESTLE, J.; VAZ, F.N.; BRONDANI, I.L. et al. Estudo da carcaça de machos Braford desmamados aos 72 ou 210 dias, abatidos aos catorze meses. Pesquisa Agropecuária Brasileira, v.34, n.11, p.2137-2144, 1999.

ROMPALA, R.E.; JONES, S.D.M.; BUCHANAN-SMITH, J.G. et al. Feedlot performance and composition of gain in late maturing steers exhibiting normal and compensatory growth. Journal of Animal Science, v.61, n.3, p.637-646, 1985.
SANTANA, G.A.O.; LOBATO, J.F.P. Efeitos de diferentes pesos e idades na desmama no desenvolvimento de bezerros e comportamento reprodutivo de vacas de corte. Eficiência reprodutiva. In: REUNIÃO ANUAL DA SOCIEDADE BRASILEIRA DE ZOOTECNIA, 20., 1983, Pelotas. Anais... Pelotas: Sociedade Brasileira de Zootecnia, 1983. p.227.

SIMEONE, A.; LOBATO, J.F.P. Efeito da lotação animal em campo nativo e do controle da amamentação no comportamento reprodutivo de vacas de corte primíparas. Revista Brasileira de Zootecnia, v.25, n.6, p.1216-1227, 1996.

STORY, C.E.; RASBY, R.J.; CLARK, R.T. et al. Age at weaning of spring-calving beef cows and the effect on cow and calf performance and production economics. Journal of Animal Science, v.78, n.6, p.1403-1413, 2000.

VAZ, R.Z.; RESTLE, J. Efeito do desmame precoce sobre o peso e desempenho reprodutivo de vacas de diferentes idades. In: REUNIÃO ANUAL DA SOCIEDADE BRASILEIRA DE ZOOTECNIA, 38., 2000, Viçosa, MG. Anais... Viçosa, MG: Sociedade Brasileira de Zootecnia, 2000. 3p.

Recebido em: 29/07/02

Aceito em: 19/12/02 